\title{
PROPOSIÇÃO E APLICAÇÃO PRÁTICA DE UM FRAMEWORK DE ANÁLISE DA SUSTENTABILIDADE
}

\author{
Marcelo Fernandes Pacheco Dias \\ Doutor em Agronegócios pela Universidade Federal do Rio Grande do Sul - UFRGS \\ Professor da Universidade Federal do Rio Grande do Sul - UFRGS \\ mfpdias@hotmail.com \\ Eugenio Avila Pedrozo \\ Doutor em Administração pelo Institut National Polytechnique de Lorraine - França \\ Professor da Universidade Federal do Rio Grande do Sul - UFRGS \\ eapedrozo@ea.ufrgs.br \\ Tania Nunes Silva \\ Doutora em Sociologia pela Universidade de São Paulo - USP \\ Professora da Universidade Federal do Rio Grande do Sul - UFRGS \\ tnsilva@ea.ufrgs.br
}

\begin{abstract}
RESUMO
$\mathrm{O}$ aumento das pressões ambientais e sociais nos negócios tem exigido que as empresas considerem essas dimensões nas suas atividades. Com isso, surge a necessidade de uma metodologia que permita a implementação do desenvolvimento sustentável nas empresas. Constata-se na literatura que há um esforço para desenvolver um modelo de gestão estratégica da sustentabilidade. Esse artigo tem como objetivo contribuir para esse esforço, por meio da identificação de complementaridades em outros modelos ainda não contemplados e, a partir daí, propor um novo framework para então fazer uma aplicação prática em duas empresas brasileiras com ações reconhecidas de sustentabilidade. O método utilizado foi um estudo qualitativo, por meio de entrevistas e pesquisa documental. Os resultados indicaram a possibilidade de complementar o modelo que já vinha sendo construído com novas contribuições e ter uma proposta mais ampliada e prática. A pesquisa nas duas empresas indicou que desenvolvem parcialmente algumas etapas do novo framework e que há necessidade de mais esforços e mais consistência no planejamento das ações de sustentabilidade dessas empresas.
\end{abstract}

Palavras-chave: Sustentabilidade; Estratégia; Agronegócios.

\begin{abstract}
The rise of environmental and social businesses has required companies to consider these dimensions in their activities. With that comes the need for a methodology that allows the implementation of sustainable development in companies. There is literature in the effort to develop a strategic management model of sustainability. This article aims to contribute to this effort by identifying complementarities in other models not yet covered, and from there to propose a new framework and then make a practical application in two Brazilian companies with stocks recognized for sustainability. The method used was a qualitative study based on interviews and documents. The results indicated the possibility of complementing the template that was already being built with new contributions and has proposed a broader practice. Research into the two companies stated that they developed partially from stages of the new framework and that there is a need for more effort and more consistency in the planning of sustainability of these enterprises.
\end{abstract}

Key words: Sustainability Analysis; Strategy; Agribusiness.

Revista de Gestão Social e Ambiental - RGSA, São Paulo, v.5 , n.1 , p. 109-122, jan./abr., 2011. 


\section{INTRODUÇÃO}

É notório o aumento das pressões de natureza ambientais e sociais nos negócios. Pressões da legislação, de clientes, consumidores e das organizações não-governamentais (ONGs) estão demandando evidências de excelência ambiental e social, de um modo crescente e irreversível. A reconfiguração econômica, que envolve a incorporação de obrigações ambientais e sociais no mecanismo econômico, está ocorrendo vagarosamente, mas efetivamente. Na essência, essa reconfiguração está ocorrendo por omissão de outras decisões, ao invés de serem planejadas e ainda gratificando processos e procedimentos que são fundamentalmente insustentáveis, entretanto o sistema econômico pode fornecer parte da solução (Boron \& Murray, 2004).

Com a sustentabilidade sendo fortemente demandada no mercado, a necessidade para uma metodologia prática que permita a implementação do desenvolvimento sustentável nos negócios e na indústria torna-se urgente (Boron \& Murray, 2004).

Para se alcançar a sustentabilidade nos negócios é indispensável a implementação de uma estratégia, com base no gerenciamento pró-ativo, que defina um curso definitivo para os objetivos do desenvolvimento sustentável (Boron \& Murray, 2004). Essa iniciativa será o principal direcionador da eliminação de muitas formas de impactos ambientais e sociais que surgem das atividades dos negócios. Com a sustentabilidade projetada no sistema desde o início e com um adequado ferramental de gerenciamento, qualquer problema ambiental ou social irá ser antecipado e o sistema irá dirigir-se para atingir seus objetivos definidos (Boron \& Murray, 2004).

Por isso, têm sido desenvolvidos vários modelos para o gerenciamento sistemático e o monitoramento do desenvolvimento sustentável (Kay et al., 1999; Robert, 2000; Robert et al, 2002; Boron \& Murray, 2004; Waage et al., 2005) e que serão discutidos individualmente na seção seguinte referente ao referencial teórico. Nesses vários modelos, há muitas similaridades e complementaridades e até aspectos antagônicos identificados. Constata-se na literatura um esforço para desenvolver um modelo de análise e gestão da sustentabilidade que agrupe, categorize e torne operacional as diversas contribuições de cada um dos modelos propostos (Robert, 2000; Robert et al., 2002; Waage et al., 2005).

Esse artigo objetiva contribuir para esse esforço, por meio da identificação de complementaridades em outros modelos ainda não contemplados, e, a partir daí, propor um novo framework, para então fazer uma aplicação prática em duas empresas brasileiras com ações reconhecidas nacionalmente de sustentabilidade.

Para isso, foi realizada uma revisão dos modelos de gestão de sustentabilidade e analisada suas complementaridades (Seção 2) com vistas a propor um novo framework (Seção 3). Com base nesse framework foi realizada uma aplicação prática de análise da sustentabilidade em duas empresas com reconhecidas ações de sustentabilidade por meio de um estudo qualitativo genérico (Seção 4), com base em entrevistas e análise de documentos. Esse estudo compreendeu a descrição dos dados coletados, classificação desses dados em categorias, segundo o framework proposto (Seção 5) e a análise e a interpretação comparativa entre empresas e com o framework proposto (Seção 6). Por fim, foram realizadas as considerações finais (Seção 7).

\section{MODELOS DE GERENCIAMENTO ESTRATÉGICO DA SUSTENTABILIDADE}

Nessa seção, são discutidos os modelos de gestão de sustentabilidade e analisadas as suas complementaridades. A Seção começa com o Modelo de Desenvolvimento Sustentável Estratégico, iniciado por Robèrt (2000), e que foi aprimorado por Robèrt et al (2002) e Waage et al (2005). Na seqüência, são apresentadas as críticas de Boron e Murray (2004) ao modelo que vem sendo desenvolvido. Por entender que o modelo Auto-Organizativo, Hierárquico e Aberto, proposto Kay

Revista de Gestão Social e Ambiental - RGSA, São Paulo, v.5, n.1, p. 109-122, jan./abr., 2011. 
(1999), traz contribuições ao aprimoramento do modelo em discussão, este também é apresentado e discutido nessa seção. Completa essa seção uma breve discussão sobre outras linhas de ação não contempladas no modelo iniciado por Robèrt (2000).

\subsection{O Framework Base - O Modelo de Desenvolvimento Sustentável Estratégico Iniciado Por Robèrt (2000)}

A escolha desse modelo para iniciar a apresentação deveu-se a este ser o resultado da primeira iniciativa de criar um framework para o gerenciamento sistemático e monitoramento do desenvolvimento sustentável. Essa iniciativa aconteceu em outubro de 1998, quando vários institutos de pesquisa foram convidados para uma reunião de trabalho no Programa Ambiental das Nações Unidas, com o propósito de apresentar seus programas e aprender uns com os outros. A reunião tinha por objetivo responder à questão "Como os conceitos e ferramentas para o desenvolvimento sustentável relacionam-se uns aos outros?" Para responder essa questão, os participantes partiram de um modelo proposto pela Organização Não-Governamental "The Natural Step", e o modelo final resultante dessa reunião foi publicado no artigo "Ferramentas e conceitos para sustentabilidade, como eles se relacionam uns aos outros?" (Robèrt, 2000).

Em síntese, o modelo tinha cinco níveis hierárquicos (Figura 1): princípios da ecosfera; condições do sistema; estratégia; atividades; conceitos e ferramentas; e efeitos negativos na natureza (Robèrt, 2000).

Dois anos após, Robèrt et al (2002) propuseram melhorias nesse modelo, mas ainda assim o modelo manteve os cinco níveis (Robèrt et al., 2002). Cada um desses níveis é detalhado melhor a seguir:

- $\quad$ Princípios do sistema global - a ecosfera: Representa o sistema global - sociedade e os ecossistemas. Envolve a compreensão dos princípios constitucionais do funcionamento da ecosfera, tais como os ciclos bioquímicos, a interdependência das espécies por meio das mudanças sociais e as leis da termodinâmica. Nessa etapa, o objetivo não é estudar a ecosfera, mas descobrir, principalmente, os diferentes mecanismos pelos quais ela pode ser destruída;

- $\quad$ Princípios para a sustentabilidade: Envolve a compreensão dos mecanismos básicos pelos quais os sistemas de sustentação da vida natural podem ser destruídos e associados a dois objetivos: desmaterialização e substituição. A desmaterialização e a substituição não estão associados somente a preocupações ecológicas, mas também a questões de saúde das pessoas, mudança cultural nos negócios, que substitui o foco na comercialização de produtos para um foco na comercialização de serviços e a equidade;

- Processos para o desenvolvimento sustentável: Foca nos processos para alcançar a sustentabilidade em conformidade com o nível anterior. Os processos previstos estão voltados para investimentos estratégicos, processos de ação social e política.

- Ações: São atividades alinhadas com os princípios do desenvolvimento sustentável, como, por exemplo, a mudança de fontes de energia não-renováveis para fontes de energia renováveis;

- Ferramentas e medidas: São os diferentes conceitos e medidas para monitorar a transição e que devem estar alinhadas com os princípios do desenvolvimento sustentável. São exemplos de medidas o Factor X, a Pegada Ecológica, Life cycle assesment - LCA, e de ferramentas como a ISO 14001 e EMAS; 
Esse modelo proposto por Robert et al. (2002) foi também debatido numa reunião que incluiu mais de 30 especialistas da academia, organizações ambientais e de sustentabilidade e executivos. Como resultado dessa reunião foram propostas sugestões para o refinamento do modelo. Três sugestões foram propostas: criar um nível intermediário entre os níveis 3 e 4 do modelo, que foi denominado de critérios e características; ampliar os detalhes dos princípios para o desenvolvimento sustentável no processo ação social; e criar uma novo processo relacionado à gestão do ciclo de vida do produto (Waage et al., 2005).

\subsection{As Contribuições de Boron E Murray (2004)}

$\mathrm{Na}$ sequência da apresentação do Modelo de Robèrt (2000), Boron e Murray (2004) criticaram o modelo que vinha sendo desenvolvido, argumentando que o modelo proposto funciona mais como uma bússola que estabelece uma direção do que uma proposta para a definição de um objetivo alvo. Essa crítica se deve a ausência de mecanismos de mapeamento dos processos que levam a insustentabilidade e de objetivos para esses processos. Por isso, o autor propôs duas contribuições principais que poderiam aprimorar o modelo proposto por Robèrt et al. (2002) e aperfeiçoado por Waage et al. (2005).

A primeira contribuição diz respeito ao conceito de processo insustentável. Um processo é insustentável quando debilita as entradas de recursos ambientais e sociais do qual depende (insustentável primário) ou que outro processo dependa (insustentável secundário). Um processo insustentável pode ser visto, por causar uma infração na disponibilidade de recursos, de uma maneira ou outra. E, de modo oposto, um processo sustentável é um modo de fazer as coisas que não tenham efeitos colaterais.

Os autores propõem criar um diagrama dos processos para que se tenha uma visualização objetiva de quais processos estão contribuindo para a insustentabilidade (Boron \& Murray, 2004). Esse diagrama é muito importante, pois sumariza os processos insustentáveis e cria uma cadeia que relaciona as causas e os efeitos desses processos. Ele pode funcionar como um mapa para a definição de objetivos, e, por conseqüência, definir ações a serem implementadas, com vistas a aumentar o grau de sustentabilidade.

Uma segunda contribuição é a definição de objetivos gerenciais. Um processo pode tornarse crescentemente sustentável, tão logo seu diagrama de processos insustentáveis seja progressivamente reduzido e a lacuna da sustentabilidade fechada.

Analisando essas contribuições, constata-se que, no modelo de Boron e Murray (2004), não são apresentados direcionadores para identificar quais poderiam ser as infrações na disponibilidade de recursos. Esses direcionadores podem ser os níveis 1 e 2 da proposta de Robèrt et al. (2002). Da mesma forma, o modelo não orienta quais ações podem ser desenvolvidas para o aprimoramento da sustentabilidade. Essa orientação é vista no nível 3 da proposta de Robèrt et al. (2002), aperfeiçoada por Waage et al. (2005). Com isso, é possível constatar a possibilidade de incorporar essas duas contribuições entre os níveis 2 e 3 do modelo.

\subsection{A Proposta de Um Sistema Auto-Organizativo, Hierárquico E Aberto (Self-Organizing Holarchic Open - Soho)}

Nessa proposta, foi sugerido um método para entender o gerenciamento ambiental, fundamentado num sistema complexo. Esse método tem como base o sistema Self- Organizing Holarchic Open (SOHO). Esse método exibe uma estrutura flexível, considera a possibilidade de surgir fenômenos emergentes e uma súbita reconfiguração do sistema, que caracterizam os sistemas complexos (Kay, Regier, Boyle, \& Francis, 1999).

Revista de Gestão Social e Ambiental - RGSA, São Paulo, v.5, n.1, p. 109-122, jan./abr., 2011. 
Esse método consiste no desenvolvimento de uma narrativa do ecossistema, que está sendo analisada, e que associada com a construção da visão e das preferências humanas cria cenários para esse ecossistema (Kay et al., 1999).

As narrativas do SOHO objetivam provir a comunidade e os tomadores de decisão com as várias possibilidades (estados) de como o futuro do ecossistema pode se desdobrar; dar um entendimento das condições sobre os quais esses estados podem ocorrer; dos trade-offs sobre os diferentes estados; fornecer adequadas soluções para assegurar a capacidade para se adaptar a essas diferentes situações; informar o nível de confiança dos estados ou o grau de incerteza de cada uma deles (Kay et al., 1999).

Contribuem para a formulação das narrativas, os seguintes conteúdos (Kay et al., 1999): definição do sistema, descrição e avaliação da integridade do ecossistema. Na construção da visão e das preferências humanas, podem ser utilizados os seguintes conteúdos: identificação dos stakeholders e outros participantes (atores); descrição do atual sistema de governança e o relacionamento institucional, assim como a evolução desse sistema; identificação dos temas mais importantes e análises por ator; definição da integridade e sustentabilidade, em termos de uma visão de futuro; mapeamento dos interesses humanos e as preferências sobre a descrição do ecossistema (Kay et al., 1999).

Uma vez construídos os cenários são definidas as ações que devem ser encorajadas A partir daí, se prevê uma estrutura da governança, gerenciamento e monitoramento das ações definidas (KAY et al., 1999).

A análise desse procedimento de construção de cenários demonstra a possibilidade de incorporar esses conteúdos numa proposta de um novo framework, como uma etapa prospectiva da organização que está sendo analisada.

\subsection{Outras Ferramentas Com Foco Na Sustentabilidade}

Várias outras ferramentas podem contribuir para a implementação de ações com foco na sustentabilidade, além das citadas por Robèrt (2000) e Robèrt et al. (2002). A seguir são discutidas cada uma delas.

Ecodesign é a consideração sistemática a respeito do desempenho do projeto, com relação aos objetivos ambientais, de saúde e segurança do trabalhador. Para isso, analisa-se o produto ao longo do seu ciclo de vida para torná-lo ecoficiente (Fiksel, 1996). Peneda e Frazão (1994) definem o Ecodesign como o desenvolvimento ambiental do produto, ou seja, há inserção da dimensão ambiental no seu processo de desenvolvimento (Peneda \& Frazão, 1994). As estratégias do Ecodesign incluem o desenvolvimento de novos conceitos para os produtos, seleção de materiais de baixo impacto, redução na quantidade de materiais, otimização das técnicas de produção e distribuição, redução do impacto ambiental no nível do usuário, aumento do tempo de uso do produto e otimização pós-uso (UNEP/IE, 1996).

Green supply chain implica integrar a dimensão ambiental na gestão da cadeia de suprimentos, incluindo design de produtos, seleção de materiais, processos de manufatura, distribuição e o gerenciamento do produto após o consumo. Os objetivos dessa ferramenta são reduzir uso de matérias-primas, eliminar resíduos e aprimorar a produtividade (Srivastava, 2007).

Produção Mais Limpa é um programa que visa a aplicação contínua de uma estratégia ambiental preventiva e integrada nos processos produtivos, nos produtos e nos serviços para reduzir os riscos relevantes aos seres humanos e ao ambiente natural. Significa realizar pequenos ajustes no processo produtivo que permitam redução da emissão e geração de resíduos diversos, por meio de pequenas reparações ou, até mesmo, pela aquisição de novas tecnologias. Adota uma abordagem

Revista de Gestão Social e Ambiental - RGSA, São Paulo, v.5, n.1, p. 109-122, jan./abr., 2011. 
preventiva, em resposta aos custos adicionais do controle da poluição e dos tratamentos do tipo final de tubo (Gunnigham \& Sinclair, 1997).

Produção limpa é um sistema de produção industrial que busca a sustentabilidade das fontes renováveis de matérias-primas, a redução do consumo de água e energia, a prevenção de geração de resíduos tóxicos e perigosos na fonte de produção, a reutilização e o reaproveitamento de materiais por reciclagem de maneira atóxica e que sejam mais eficientes em termos energéticos, a geração de produtos de longa vida útil, seguros e atóxicos ao homem e ao ambiente natural, cujos restos, inclusive as embalagens, tenham reaproveitamento atóxico e sejam recicláveis (Nascimento, Lemos \& Mello, 2008).

Programa Emissão Zero baseia-se nos princípios que nenhum ecossistema produz resíduos, porque o resíduo de uma espécie serve de alimento para outra; assim a matéria movimenta-se em círculo infindável pela teia da vida, ou seja, a energia impulsionadora do ciclo biológico provém do sol; a multiplicidade garante a regeneração; a vida depende da cooperação. São objetivos desse programa a produção zero de resíduo líquido, gasoso ou sólido; todas as entradas são utilizadas na produção; e quando houver resíduo, podem ser utilizados por outras indústrias (Nascimento, Lemos \& Mello, 2008).

A neutralização do carbono se refere à compensação das emissões de gases geradores do efeito estufa, produzidos por empresas com o objetivo de contribuir para minimização do efeito estufa. Essa compensação pode se dar pelo plantio de árvores, aterros sanitários que reduzem a emissão de gases, na produção de energia limpa (eólica, fotovoltaica) para substituir energia fóssil (Nascimento, Lemos \& Mello, 2008).

\section{METODOLOGIA}

Essa pesquisa foi classificada quanto à abordagem como qualitativa, dada as suas características de ser rica em descrições, como indutiva, quanto ao seu modo de análise, por utilizar entrevistas e documentos como dados e por objetivar entender um determinado fenômeno (Merriam, 1988).

Quanto ao tipo, foi classificada como estudo qualitativo genérico, já que se caracteriza por ter uma análise com base em conceitos de um framework, por não se classificar nos demais tipos (Merrian, 1998). Logo, a primeira parte da pesquisa consistiu na revisão da literatura sobre os modelos de gestão da sustentabilidade e a proposição de um framework, a partir do estudo das complementaridades dos modelos.

A segunda etapa consistiu na aplicação prática do framework em duas empresas: uma empresa brasileira do setor florestal e outra de alimentos, ambas com reconhecidas ações de sustentabilidade e que não foram identificadas, atendendo a solicitação de ambas.

Quanto ao plano de coleta de dados, foram utilizados dados primários coletados por meio de entrevista com funcionários ligados as empresas e ao tema. As entrevistas foram gravadas. Também utilizou-se dos relatórios de sustentabilidade, disponibilizados pelas empresas. A coleta de dados foi realizada em maio de 2008.

Como tratamento dos dados foi realizado uma análise de conteúdo das entrevistas e dos documentos de cada empresa. Essas informações coletadas foram classificadas segundo as categorias do framework prévio. A análise de conteúdo é considerada um conjunto de técnicas que envolve a classificação dos conceitos, a sua codificação e a sua categorização. Nesse processo, o pesquisador deve possuir amplo conhecimento teórico e dominar os conceitos básicos das teorias que estariam alicerçando o conteúdo das mensagens (Trivinõs, 1987). Esse método prevê três fases fundamentais, denominadas de pré-análise, descrição analítica e interpretação referencial (Bardin, 1977). Para a análise desses dados foi feita a utilização do software NVivo.

Revista de Gestão Social e Ambiental - RGSA, São Paulo, v.5, n.1, p. 109-122, jan./abr., 2011. 


\subsection{Framework Para A Gestão Estratégica da Sustentabilidade Nas Empresas}

Antes de iniciar a apresentação propriamente dita do framework, cabe fazer a discussão das premissas que envolveram a proposta. Para facilitar essa discussão, apresenta-se uma questão bastante típica de quando se discute o tema sustentabilidade. Uma determinada ação, produto ou organização é sustentável ou não é sustentável?

Quando se tenta responder essa questão, na prática, se constata uma séria de trade-offs. Por exemplo, um determinado produto alterou sua matéria-prima, o que possibilitou consumir menor quantidade, comparativamente com outra matéria-prima, entretanto essa última tornava o produto mais durável. Logo, essa é uma inovação sustentável? Depende do que é mais importante, ou seja, a menor quantidade utilizada poderia estar vindo de uma fonte não-renovável, escassa, apesar de ser economicamente viável, enquanto o produto com maior consumo de matéria-prima poderia vir de uma fonte renovável.

Uma primeira observação desse exemplo indica que a sustentabilidade exige o conhecimento do ecossistema global, um diagnóstico da interferência dos processos e produtos da organização e da definição do que é mais prioritário, e dos objetivos. Ações aleatórias podem promover melhorias em aspectos poucos importantes ou prejudicar recursos mais importantes para a sustentabilidade da sociedade.

Uma segunda observação diz respeito ao processo de melhoria. Nesse sentido, não se entende uma organização como sustentável ou insustentável, mas como um processo dinâmico, de aproximação, que pode não ter fim, ou seja, uma vez iniciada a busca pela sustentabilidade, esta pode aprimorar-se ao longo do tempo, tornando-se cada vez mais eficiente, mas nunca chegando a um estado ideal (Iyer-Raniga \& Treloar, 2000).

Uma terceira observação indica que a sustentabilidade exige a busca de equilíbrio entre pelo menos três pilares (ambiental, social e econômico), apesar dessa posição não ser unânime. Essa falta de unanimidade pode ser observada na publicação de Egri e Pinfield (2001) que sistematiza os vários posicionamentos sobre essa questão.

Considerando-se as premissas de visão global, diagnóstico, escolha, definição de objetivos, sustentabilidade como um processo que contempla, pelos menos, os pilares ambiental, social e econômico e, principalmente, a revisão da literatura, foi proposto framework para a gestão estratégica da sustentabilidade nas empresas (Figura 1). A primeira etapa do framework exige a descrição dos princípios do sistema global (1). Essa etapa implica descobrir os diferentes mecanismos que causam a destruição do sistema global (ecológico + ambiental).

A segunda etapa compreende a construção de cenários para a organização (2). Essa etapa visa proporcionar aos tomadores de decisão, cenários possíveis sobre os aspectos da sustentabilidade que podem afetar a organização. Busca-se identificar nesses cenários, principalmente, a contribuição da empresa para a destruição do sistema global e também como esta pode ser afetada. Essa etapa é dividida em duas partes: uma delas trata da descrição socioambiental e a construção da visão e das preferências dos interessados na organização (3). A outra consiste num diagnóstico (4) que tem como base o mapeamento dos processos insustentáveis, na definição de objetivos e metas. A seleção dos processos e dos objetivos deve ser orientada pelos cenários construídos para a organização na etapa anterior. Na sequência são descritas as linhas de atuação (5) para aprimoramento dos objetivos insustentáveis ${ }^{5}$ com vistas a reduzir ou minimizar os processos insustentáveis. Essas linhas estratégicas de atuação podem ser aplicadas por meio de quatro processos estratégicos (6) previstos na etapa seguinte do modelo. As ações (7) são atividades alinhadas com as estratégias de atuação e com os processos estratégicos. O sistema de gestão (8) busca organizar a implementação das ações previstas. As ferramentas (9) são processos 
administrativos para a implantação das ações previstas e os sistemas de medição (10) são indicadores para medir e monitorar a transição e que devem estar alinhados com os objetivos.

\begin{tabular}{|c|c|c|}
\hline ORDEM & ETAPAS DO FRAMEWORK & AUTORES \\
\hline 1 & PRINCÍPIOS DO SISTEMA GLOBAL & $\begin{array}{l}\text { Robèrt (2000); Robèrt et al. } \\
\text { (2002) }\end{array}$ \\
\hline 2 & CENÁRIOS PARA A ORGANIZAÇÃO & \multirow[b]{2}{*}{ Kay et al. (19 } \\
\hline 3 & \begin{tabular}{c|c} 
Descrição & Construção da visão e das \\
$\begin{array}{c}\text { socioambiental da } \\
\text { organização. }\end{array}$ & $\begin{array}{c}\text { preferências dos interessados na } \\
\text { organização. }\end{array}$ \\
\end{tabular} & \\
\hline 4 & $\begin{array}{c}\text { DIAGNÓSTICO: } \\
\text { MAPEAMENTO DOS PROCESSOS INSUSTENTÁVEIS } \\
\text { DEFINIÇÃO DOS OBJETIVOS E METAS. }\end{array}$ & Boron e Murray (2004) \\
\hline \multirow[t]{2}{*}{5} & LINHAS ESTRATÉGICAS DE ATUAÇÃO & \multirow[b]{2}{*}{$\begin{array}{l}\text { Robèrt (2000); } \\
\text { Robèrt et al. (2002); } \\
\text { Waage et al. 2005; } \\
\text { Fiksel (1996); } \\
\text { UNEP (1996); } \\
\text { Srivastava (2007); } \\
\text { Gunnigham e Sinclair (1997); } \\
\text { Nascimento, Lemos e Mello (2008) }\end{array}$} \\
\hline & $\begin{array}{l}\text { Redução e eliminação dos resíduos; prevenção de geração de } \\
\text { resíduos tóxicos; neutralização do carbono; aumento da } \\
\text { produtividade dos insumos; otimização das técnicas de } \\
\text { produção e distribuição; otimização do tempo de uso do } \\
\text { produto; reciclagem e otimização pós-uso; circuitos fechados de } \\
\text { materiais e resíduos; desmaterialização; substituição de } \\
\text { materiais e processos; novos conceitos para os produtos; } \\
\text { negócios com foco em serviços; reinvestimento no capital } \\
\text { natural pela restauração, sustentação e expansão do habitat } \\
\text { natural; investimento em recursos e competências para } \\
\text { tecnologias mais limpas; desenvolvimento de produtos } \\
\text { sustentáveis incluindo a população de baixa renda; } \\
\text { responsabilidade social, saúde, segurança e equidade. }\end{array}$ & \\
\hline \multirow[t]{2}{*}{6} & PROCESSOS ESTRATÉGICOS DE ATUAÇÃO & \multirow{2}{*}{$\begin{array}{l}\text { Robèrt (2000); Robèrt et al. } \\
\text { (2002); Waage et al. (2005) }\end{array}$} \\
\hline & $\begin{array}{l}1 \text {.Processos de investimento estratégico; } 2 \text {. Processos de ação } \\
\text { social; } 3 \text {. Processo de gestão do ciclo de vida; } 4 \text {. Processos de } \\
\text { ação política. }\end{array}$ & \\
\hline 7 & AÇÕES & $\begin{array}{l}\text { Robèrt (2000); Robèrt et al. } \\
\text { (2002); Waage et al. (2005) }\end{array}$ \\
\hline \multirow[t]{2}{*}{8} & SISTEMA DE GESTÃO & \multirow{2}{*}{$\begin{array}{l}\text { Robèrt (2000); Robèrt et al. } \\
\text { (2002); Waage et al. (2005) }\end{array}$} \\
\hline & ISO 14001, Emas & \\
\hline \multirow[t]{2}{*}{9} & FERRAMENTAS & \multirow{2}{*}{$\begin{array}{l}\text { Robèrt }(2000) ; \quad \text { Robèrt } \text { et al. } \\
(2002) ; \text { Fiksel (1996); UNEP } \\
\text { (1996); Srivastava (2007); } \\
\text { Gunnigham e Sinclair (1997); } \\
\text { Nascimento, Lemos e Mello (2008) }\end{array}$} \\
\hline & $\begin{array}{l}\text { Ecodesign, Green supply chain, P+L, Produção Limpa, } \\
\text { Emissão Zeri, Neutralização de carbono, Norma AA } 1000\end{array}$ & \\
\hline \multirow[t]{2}{*}{10} & SISTEMAS DE MEDIÇÃO & \multirow{2}{*}{$\begin{array}{l}\text { Robèrt (2000); Robèrt et al. } \\
\text { (2002) }\end{array}$} \\
\hline & $\begin{array}{l}\text { FATOR X, PEGADA ECOLÓGICA, ANÁLISE DO } \\
\text { CICLO DE VIDA. }\end{array}$ & \\
\hline
\end{tabular}

Figura 1: Framework para a gestão da sustentabilidade nas empresas

\section{DESCRIÇÃO E CLASSIFICAÇÃO DAS INFORMAÇÕES DE SUSTENTABILIDADE DAS EMPRESAS}

Nessa etapa são descritas e classificadas as informações relacionadas à sustentabilidade, identificadas na entrevista realizada, na análise do relatório de sustentabilidade da empresa e nas

Revista de Gestão Social e Ambiental - RGSA, São Paulo, v.5, n.1, p. 109-122, jan./abr., 2011. 
informações disponíveis nos sítios eletrônicos. Visa identificar como os dados disponibilizados pela empresa se refletem no framework proposto.

\subsection{Empresa A}

Cenários socioambientais da organização: Na etapa de "construção da visão e das preferências humanas" a empresa vem desenvolvendo duas ações e que se relacionam a essa etapa do modelo. A primeira é relacionada ao que a empresa convencionou chamar de matriz de materialidade. Essa matriz busca identificar quais questões envolvendo as operações são consideradas mais importantes para as partes interessadas e o impacto que têm ou podem vir a ter, no desenvolvimento dos negócios da empresa. A segunda ação, complementar a primeira, visa estruturar uma matriz de prioridades das comunidades onde a empresa atua.

Diagnóstico: Foi verificado que a empresa possui um conjunto e objetivos e metas propostos. Esse conjunto de metas é relacionado aos temas governança, relacionamento com as partes interessadas, investimentos sociais, meio ambiente, responsabilidade pela cadeia de suprimentos, empregados e clientes.

Linhas de atuação para aprimoramento dos objetivos sustentáveis: Sobre informações de "redução de resíduos" foram identificados o controle das emissões e dos resíduos na produção de celulose e o controle da geração e da destinação dos resíduos sólidos.

$\mathrm{Na}$ linha de atuação sobre "aumento da produtividade dos insumos" foram classificadas as informações sobre o controle do consumo de insumos específicos na produção de celulose, controle do consumo de combustíveis e energia não-renováveis.

$\mathrm{Na}$ linha de atuação "substituição de materiais e processos" foi classificada a informação sobre a certificação agroflorestal. Essa certificação atesta que toda a matéria-prima utilizada possui, no mínimo, $70 \%$ de madeira oriunda de manejo florestal sustentável, e que o restante provém de fontes não-controversas. Uma segunda informação classificada nessa linha foi o manejo integrado de pragas e doenças, desenvolvido pela empresa, que objetiva empregar o mínimo necessário de defensivos agrícolas. Nessa mesma linha, foi classificada também a informação sobre o controle da geração e do consumo de energia renováveis e a comercialização, sob a forma de corretivo de solo, da totalidade dos resíduos da caustificação.

$\mathrm{Na}$ linha de atuação "circuitos fechados de materiais" classificou-se a informação sobre o aprimoramento nos processos de reaproveitamento de água e destinação final de efluentes.

$\mathrm{Na}$ linha de atuação "responsabilidade social" com foco interno à organização foram classificadas várias informações obtidas com foco na saúde e bem-estar dos empregados, tais como programas de vacinação, suporte ao planejamento à aposentadoria, programas de apoio aos dependentes químicos, de reabilitação profissional, aposentadoria complementar, programas de estagiários, programa menor aprendiz e controle do clima interno e dos acidentes de trabalho. Com foco externo foram relatadas ações voltadas à educação, saúde, segurança alimentar, arranjos produtivos locais e inclusão social, acordo com os quilombolas, apoio à estratégias de desenvolvimento regional que contemplem comunidades de baixa renda.

Sobre a atuação em "neutralização de carbono" foi identificado o processo de melhoria e controle da eficiência de emissões de gases do efeito estufa, associadas às suas atividades industriais, com vistas a entrada no mercado de crédito de carbono.

A empresa atua por meio de "investimento em recursos e competências para tecnologias mais limpas" considerando o relatado que a empresa desenvolve pesquisa do manejo do solo para avaliar a influência do manejo florestal tanto na quantidade quanto na qualidade de matéria orgânica em solos sob plantações de eucalipto.

Revista de Gestão Social e Ambiental - RGSA, São Paulo, v.5, n.1, p. 109-122, jan./abr., 2011. 
Na linha de atuação "reinvestimento em capital natural" foi classificada a informação sobre o desenvolvimento de medidas para conhecer e preservar a biodiversidade das regiões onde atua e também sobre a criação de reservas particulares do patrimônio natural.

Também foram relacionadas como forma de atuação, tendo em vista a sustentabilidade, as ações de "educação ambiental". Para atender esse objetivo, foram relatados encontros com produtores e a criação de um programa de engajamento com cerca de 80 profissionais, de diversos níveis hierárquicos, que receberam treinamento sobre o novo modelo de engajamento da empresa.

Processos de atuação: Foram relatadas as atuações por meio de "investimentos estratégicos" como, por exemplo, a instalação de leitos de secagem para o tratamento final dos resíduos para serem comercializados na forma de corretivo de solos. Sobre processos de "ação social" foram relatadas as ações de diálogo com as organizações não governamentais (ONGs) e a presença em fóruns sociais. Os processos de "gestão do ciclo de vida" foram evidenciados pelo relato que trata sobre a necessidade de engajamento dos fornecedores na observância dos princípios de sustentabilidade da empresa.

Sistemas de Gestão e ferramentas: Foi identificado que a empresa possui o sistema de gestão ISO 14.001 e outros específicos de sua atividade.

Indicadores: Em relação ao controle estratégico dos indicadores foi relatado que o controle estratégico tem como base o modelo Balanced Scorecard que é apresentado sob quatro perspectivas: criação de valor, satisfação do cliente, processos internos e aprendizado e monitoramento. Vários indicadores foram relatados para o monitoramento da sustentabilidade.

Foram citados o controle do clima interno, dos consumos específicos na produção de celulose, das emissões e resíduos na produção de celulose, do consumo e geração de energia, de combustíveis renováveis e não-renováveis, da geração e destinação dos resíduos sólidos, da emissão dos gases do efeito estufa, do estoque de carbono, dos acidentes de trabalho e o monitoramento climático.

Definição da estrutura: Para melhorar a gestão dos investimentos sociais da empresa foi relatado a criação de um instituto cujo objetivo é promover o desenvolvimento comunitário sustentável a partir do fortalecimento do capital humano, social e econômico, priorizando comunidades carentes nas áreas de atuação. O foco dos investimentos do instituto será em educação e geração de renda, por meio de projetos definidos em conjunto com as comunidades.

Sobre a estrutura existente, constatou-se informações sobre uma estrutura de sustentabilidade composta por uma diretoria de sustentabilidade e relações corporativas, uma gerência de sustentabilidade e uma gerência de qualidade e meio-ambiente.

\subsection{Empresa B}

Princípios do sistema global: Adotou como princípios fundamentais da sua atuação as metas do milênio da Organização das Nações Unidas, que trata de um compromisso assumido por 191 países, em setembro de 2000, em relação a oito objetivos.

Construção da visão e das preferências humanas e objetivos estratégicos: Tendo como base as metas do milênio, a empresa estruturou um conjunto de objetivos de atuação socioambiental. São eles: gerar ocupação, renda e cooperativismo para populações fora dos mercados de produção e consumo; estimular o empreendedorismo das classes populares; capacitar adultos para a empregabilidade e a colaboração grupal no trabalho; consolidar um amplo sistema de reciclagem e reaproveitamento de materiais; contribuir para a preservação de ambientes naturais degradados, reduzindo o descarte de materiais; estimular e estabelecer parcerias com diversos setores; integrar e fortalecer a gestão pela responsabilidade social empresarial.

Diagnóstico: Foi verificado que a empresa possui um conjunto de objetivos e metas propostos para as ações sociais relacionadas às ações sociais externas. 
Linhas de atuação para aprimoramento dos objetivos sustentáveis: Na linha de atuação "redução de resíduos" foram classificadas ações de controle de afluentes e emissões, resultantes do processamento industrial e dos seus veículos.

Em relação ao "aumento da produtividade dos insumos" foram relatadas ações de controle do consumo de água, energia e combustíveis.

$\mathrm{Na}$ linha de atuação "substituição de materiais e processos" foi classificada a preocupação com o aprimoramento dos usos dos recursos nas melhorias implementadas como, por exemplo, a melhoria no reaproveitamento de ar comprimido utilizado na moldagem das garrafas.

$\mathrm{Na}$ atuação sobre "responsabilidade social" interna, foi relatado que a empresa proporciona a participação nos resultados da empresa, plano de saúde próprio, serviços ambulatoriais, assistência odontológica, seguro de vida, serviço de restaurante ou vale- alimentação, financiamentos de casas, automóveis e eletrodomésticos e subsídios para a educação e treinamentos. Na linha de atuação "responsabilidade social" atua externamente, principalmente, por meio de projetos sociais. Ele atua, também, em diversos programas sociais, apóia projetos comunitários, os municípios por meio de doações para diferentes fundos municipais dos direitos da criança e projetos culturais.

Visa a sustentabilidade por meio da "educação ambiental", proporcionando programas de educação ambiental.

Processos e políticas de atuação: A atuação de sustentabilidade é focada em "processos sociais". Ela atua com ONGs para a consultoria e fiscalização dos projetos financiados e com associações e cooperativas para execução dos projetos. Atua também por meio do processo de "gestão do ciclo de vida" por meio de princípios de conduta para os seus fornecedores. Nesse conjunto de princípios incluem-se exigências sobre regulamentações aplicadas a produção e distribuição; não se utilizar de trabalho infantil; não usar trabalho forçado, nem abusivo; respeitar os acordos coletivos; pagar os salários, benefícios e horas extras de acordo com as leis locais; cumprir as normas de saúde, segurança e meio ambiente.

Indicadores: Para avaliação dos objetivos definidos nos projetos de sociais, a empresa criou um conjunto de objetivos, que são: número de unidades de reciclagem apoiados na região x número de galpões existentes; de trabalhadores beneficiados e de vagas geradas; tonelagem de materiais processada; subprodutos gerados - tonelagem; valor investido - série histórica; valor alavancado de parcerias; famílias e crianças beneficiadas; número de cidades atendidas; percentagem de embalagens reaproveitadas x \% produzido; desempenho dos indicadores socioeconômicos da região; elevação da renda mensal per capita.

Outros indicadores em relação ao público interno e com foco social são monitorados como de: perfil dos colaboradores (gênero, cor, deficientes, menores aprendizes), do corpo funcional (número de empregados, grau de formação, idade, tempo de serviço, número de dependentes e estagiários), número de procedimentos de assistência médica, gastos totais com benefícios (alimentação, saúde, segurança do trabalho, educação, lazer, capacitação, creche, vale-transporte e outros), taxa de atração e retenção de funcionários, indicadores de acidentes de trabalho.

Em relação ao público externo e com foco social são monitorados indicadores de gastos com os projetos culturais e comunitários e com assistência social.

Em relação as ações internas e com foco ambiental são monitorados os consumos anuais de energia, energia elétrica por litro produzido, água por litro produzido, de água, total de diesel pela frota, quantidade anual de resíduos sólidos produzidos, de resíduos sólidos produzidos por litro produzido e de resíduos reciclados.

Em relações as ações externas e com foco ambiental são monitoradas as quantidades de embalagem recicladas. 
Definição da estrutura: Para o gerenciamento dos projetos sociais foi criado um instituto que é formado por um conselho curador, um conselho deliberativo, um conselho diretivo, um conselho fiscal, um diretor executivo e um gerente administrativo.

\section{ANÁLISE E INTERPRETAÇÃO DA GESTÃO DA SUSTENTABILIDADE DAS DUAS EMPRESAS}

Uma vez feita a descrição e a classificação das ações de ambas as empresas em relação ao framework, se buscará, nessa seção, comparar o que ambas as empresas estão realizando em termos de gestão da sustentabilidade.

A análise realizada na Figura 2 indica o que as empresas não realizaram ou realizaram parcialmente nesse estágio do framework e nas etapas de planejamento de suas ações de sustentabilidade. Isso tem implicações significativas, já que as empresas não conseguem ter uma perspectiva ampla de quais são os diferentes mecanismos que contribuirão para a degradação ambiental e social.

\begin{tabular}{|l|l|l|}
\hline & \multicolumn{1}{|c|}{ EMPRESA A } & \multicolumn{1}{c|}{ EMPRESA B } \\
\hline $\begin{array}{l}\text { Princípios do } \\
\text { sistema global }\end{array}$ & $\begin{array}{l}\text { Não desenvolveu explicitamente o } \\
\text { entendimento de como suas operações } \\
\text { podem afetar as dimensões ambientais e } \\
\text { sociais. }\end{array}$ & $\begin{array}{l}\text { Adotou como princípios do sistema global as } \\
\text { Metas do Milênio, formuladas pela ONU. Essas } \\
\text { metas têm ênfase predominantemente social. A } \\
\text { dimensão ambiental ficou pouco destacada. }\end{array}$ \\
\hline
\end{tabular}

Figura 2: Análise das ações de sustentabilidade das empresas em relação a etapa do framewok "princípios do sistema global"

Fonte: Elaborado pelos autores.

Observando-se a análise da Figura 3, verifica-se que ambas as empresas não possuem uma descrição socioambiental da organização. Essa descrição poderia provir os tomadores de decisão de como o futuro das dimensões socioambientais das organizações poderiam se desdobrar; dar um entendimento das condições de cada um desses desdobramentos, dos trade-offs e informar o grau de incerteza. Enfim, possibilitaria construir um cenário de futuro que subsidiaria as ações organizacionais no presente.

\begin{tabular}{|c|c|c|}
\hline \multicolumn{3}{|c|}{ CENÁRIOS } \\
\hline & EMPRESA A & EMPRESA B \\
\hline $\begin{array}{l}\text { Descrição socioambiental da } \\
\text { organização }\end{array}$ & $\begin{array}{l}\text { Não foi evidenciada a construção de } \\
\text { cenários para a organização }\end{array}$ & $\begin{array}{l}\text { A mesma análise feita para a } \\
\text { empresa A se aplica a empresa B. }\end{array}$ \\
\hline $\begin{array}{l}\text { Construção da visão e das } \\
\text { preferências dos interessados na } \\
\text { organização. }\end{array}$ & $\begin{array}{l}\text { Pretende fazer essa construção por } \\
\text { meio da matriz de materialidade que } \\
\text { implica definir as prioridades dos } \\
\text { stakeholders. Pretende que essa matriz } \\
\text { seja aprimorada pela ação de } \\
\text { engajamento dos funcionários. Essa } \\
\text { ação objetiva construir uma matriz de } \\
\text { prioridade das comunidades. }\end{array}$ & $\begin{array}{l}\text { Fez a construção da visão e das } \\
\text { preferências humanas a partir das } \\
\text { metas do milênio. Não considerou a } \\
\text { participação dos stakeholders locais } \\
\text { na definição dessas preferências. }\end{array}$ \\
\hline
\end{tabular}

Figura 3: Análise das ações de sustentabilidade das empresas em relação a etapa do framewok "cenários" Fonte: Elaborado pelos autores.

Já em relação a construção da visão e das preferências dos interessados na organização sobre as ações que desenvolvem (figura 3), ambas as organizações já começam a incorporar na gestão da sustentabilidade algum processo de construção que pode levar as prioridades com vistas a sustentabilidade. No caso da empresa A esse processo pretende incorporar os stakeholders, enquanto na empresa B essa participação ainda não é prevista nessa etapa. Dada a não identificação 
de ações correspondentes às primeiras etapas do framework é possível inferir que esse processo poderá levar a uma redução, na visão dos participantes, das prioridades, dada a falta de uma visão ampla do sistema global e da descrição socioambiental da organização.

A análise das informações sobre sustentabilidade das empresas em relação a etapa do framewok "diagnóstico" (Figura 4) foi identificada parcialmente em ambas as empresas, em razão da não constatação de mapas dos processos insustentáveis. A construção desses mapas possibilitaria relacionar as causas e os efeitos dos processos que levam a insustentabilidade. Por meio deles seria possível avaliar o atual grau de insustentabilidade e definir metas para o aprimoramento. Entretanto, a análise dessa etapa indicou que as empresas monitoram vários objetivos, mas há inconsistência entre objetivos, metas, ações e indicadores selecionados. Isso demonstra a necessidade de melhorar a sistematização das decisões estratégicas. Como não foi identificada nas empresas as etapas anteriores do framework, isso induz a pensar que a definição de objetivos é oriunda de uma decisão não planejada. Dado que o tema sustentabilidade exige visão global do sistema que está sendo analisado, processos de planejamento, como o proposto, podem contribuir significativamente com esse intuito, entretanto isso não invalida a inclusão de objetivos, ações e metas não planejadas.

\begin{tabular}{|c|c|c|}
\hline \multicolumn{3}{|c|}{ DIAGNÓSTICO } \\
\hline & EMPRESA A & EMPRESA B \\
\hline $\begin{array}{l}\text { Mapeamento dos } \\
\text { processos } \\
\text { insustentáveis e } \\
\text { definição dos } \\
\text { objetivos e metas. }\end{array}$ & $\begin{array}{l}\text { Não foi identificado qualquer processo de mapeamento dos processos } \\
\text { insustentáveis. Entretanto, a empresa monitora vários objetivos. Nem } \\
\text { todos os objetivos têm metas e também não foram evidenciados planos } \\
\text { de ações para todos os objetivos. Isso indica uma certa aleatoriedade na } \\
\text { busca dos objetivos. }\end{array}$ & $\begin{array}{c}\text { A mesma análise } \\
\text { feita para a empresa } \\
\text { A se aplica a } \\
\text { empresa B. }\end{array}$ \\
\hline
\end{tabular}

Figura 4: Análise das ações de sustentabilidade das empresas em relação a etapa do framewok "diagnóstico" Fonte: Elaborado pelos autores.

A comparação da Figura 5 com a etapa linhas de ação estratégica, proposta no framework (Figura 1), indica que ambas as empresas não utilizam de todas as linhas de ação previstas no framework, caracterizando-se numa oportunidade de ampliar os modos de atuação. Foi adicionada nas possibilidades de estratégias de ação a "educação ambiental", relatada em ambas as empresas.

Comparando as duas empresas, a A se utiliza de um conjunto maior de linhas de atuação. Utilizar uma ou outra linha de atuação não significa que a empresa esgotou as possibilidades de uso dessa linha nas suas ações, mas apenas indica que faz uso desses tipos.

\begin{tabular}{|c|c|c|}
\hline \multicolumn{3}{|c|}{ LINHAS DE ATUAÇÃO PARA APRIMORAMENTO DOS OBJETIVOS INSUSTENTÁVEIS } \\
\hline & EMPRESA A & EMPRESA B \\
\hline Redução de resíduos & $\mathrm{X}$ & $\mathrm{X}$ \\
\hline Aumento da produtividade dos insumos & $\mathrm{X}$ & $\mathrm{X}$ \\
\hline Substituição de materiais e processos & $\mathrm{X}$ & $\mathrm{X}$ \\
\hline Circuitos fechados de materiais & $\mathrm{X}$ & \\
\hline Responsabilidade social & $\mathrm{X}$ & $\mathrm{X}$ \\
\hline Neutralização do carbono & $\mathrm{X}$ & \\
\hline Investimento em recursos e competências para tecnologias mais limpas & $\mathrm{X}$ & \\
\hline $\begin{array}{l}\text { Reinvestimento no capital natural pela restauração, sustentação e expansão } \\
\text { do habitat natural }\end{array}$ & $\mathrm{X}$ & \\
\hline Educação ambiental & $\mathrm{X}$ & $\mathrm{X}$ \\
\hline
\end{tabular}

Figura 5: Estratégias de atuação utilizadas pelas duas empresas analisadas comparativamente com o framewok proposto.

Fonte: Elaborado pelos autores.

Observando-se a Figura 6, constata-se que ambas as empresas utilizam-se dos mesmos processos para implantação das suas linhas de atuação. 


\begin{tabular}{|l|c|c|}
\hline \multicolumn{2}{|c|}{ ESTRATÉGIAS } \\
\hline & EMPRESA A & EMPRESA B \\
\hline Processos de investimento estratégico & $X$ & $X$ \\
\hline Processos de ação social & $X$ & $X$ \\
\hline Processo de gestão do ciclo de vida & $X$ & $X$ \\
\hline Processos de ação política & & \\
\hline
\end{tabular}

Figura 6: Processos de atuação utilizados pelas duas empresas analisadas comparativamente ao framewok proposto.

Fonte: Elaborado pelos autores.

No que diz respeito aos sistemas de gestão da sustentabilidade e ferramentas, nota-se que enquanto a empresa A faz uso desses sistemas, a B não faz (Figura 7).

\begin{tabular}{|c|c|c|}
\hline & EMPRESA A & EMPRESA B \\
\hline Sistema de gestão & ISO 14.001 & Não possui \\
\hline Ferramentas & $\begin{array}{c}\text { Certificados específicos da } \\
\text { atividade }\end{array}$ & Não possui \\
\hline
\end{tabular}

Figura 7: Comparativo do uso de sistemas de gestão ambiental e ferramentas entre as empresas Fonte: Elaborado pelos autores.

A empresa A utiliza o sistema Balanced Scorecard de controle estratégico (Figura 8). Esse sistema, no entanto, não se mostrou eficiente, pois não considera as etapas de princípios do sistema global, e nem os cenários, as linhas de atuação e os processos. Suas dimensões de monitoramento são mais adaptadas aos negócios comerciais. A empresa B utiliza os indicadores do projeto social como referência para os indicadores. Como já foi dito anteriormente, verificou-se a presença de inconsistência entre objetivos, metas, ações e indicadores, selecionados em ambas as empresas, excluindo os indicadores dos projetos sociais da empresa B.

\begin{tabular}{|c|c|c|}
\hline & EMPRESA A & EMPRESA B \\
\hline Indicadores & $\begin{array}{c}\text { Balanced Scorecard } \\
\text { Outros indicadores }\end{array}$ & $\begin{array}{c}\text { Projeto social } \\
\text { Outros indicadores }\end{array}$ \\
\hline
\end{tabular}

Figura 8: Comparativo do uso de indicadores entre as empresas Fonte: Elaborado pelos autores.

Comparando-se as duas empresas na estrutura criada para o gerenciamento da sustentabilidade, verifica-se a existência de diretoria e gerencia própria na empresa A, enquanto na empresa B não.

\begin{tabular}{|l|l|l|}
\hline & \multicolumn{1}{|c|}{ EMPRESA A } & \multicolumn{1}{|c|}{ EMPRESA B } \\
\hline \multirow{5}{*}{ Estrutura } & $\begin{array}{l}\text { Evidencia-se a criação de uma estrutura } \\
\text { (fundação), que tem por objetivo gerenciar os } \\
\text { aspectos sociais. Não se verificou uma estrutura } \\
\text { semelhante para a gestão ambiental. } \\
\text { Já possui uma diretoria e uma gerência de } \\
\text { sustentabilidade. }\end{array}$ & $\begin{array}{l}\text { Evidencia-se a criação de uma estrutura } \\
\text { (instituto), que tem por objetivo gerenciar os } \\
\text { aspectos sociais e ações de reciclagem. Não se } \\
\text { verificou uma estrutura semelhante para a } \\
\text { gestão ambiental. }\end{array}$ \\
\hline
\end{tabular}

Figura 9: Estrutura utilizada pelas duas empresas analisadas comparativamente com o framewok proposto Fonte: Elaborado pelos autores.

As empresas estão estruturando uma fundação ou instituto para a gestão dos programas sociais. Um questionamento surge dessa atitude. Será que a divisão das atribuições sociais das ambientais não compromete a visão global essencial para a adequada gestão do tema? 


\section{CONSIDERAÇÕES FINAIS}

Esse artigo teve como objetivo contribuir para o esforço voltado à construção de um framework prático que permita a implementação do desenvolvimento sustentável nas empresas, pela identificação de complementaridades em outros modelos ainda não contemplados, para então discutir como está a gestão estratégica da sustentabilidade em duas empresas brasileiras de classe mundial.

Duas informações verificadas nas preocupações sobre sustentabilidade nas empresas podem ser incorporadas ao framework para a gestão estratégica da sustentabilidade. A primeira diz respeito a preocupação com a estrutura organizacional. Ambas as empresas indicaram a necessidade de se criar uma estrutura própria para fazer essa gestão, porém apontando uma separação da dimensão social, da ambiental. Essa evidência induz a uma proposta de pesquisa futura sobre as consequências desse modo de organização. A segunda informação diz respeito a "educação ambiental", como forma de alcançar a sustentabilidade. Como o tema sustentabilidade envolve a quebra do paradigma vigente, que tem foco exclusivamente econômico, dificilmente haverá aprimoramentos na sustentabilidade sem atuações estratégicas internas e externas a organização com foco em "educação ambiental". Essa constatação também induz a uma segunda pergunta: as organizações que visam a sustentabilidade não deveriam focar também em ações de "educação sobre responsabilidade social"?

As constatações nas empresas também indicaram que ambas estão incorporando processos e conteúdos, com vistas a uma ação mais pró-ativa. Entretanto, etapas que possibilitam sistematizar o conhecimento sobre como as operações podem afetar a sustentabilidade, cenários para a busca próativa da sustentabilidade e diagnósticos dos processos insustentáveis ainda são muito carentes. A falta desses conteúdos não possibilita a construção de objetivos sistêmicos que o tema exige e que sejam consistentes com ações e metas. Essa carência ficou evidenciada por alguns objetivos sem metas, ações e indicadores correspondentes, indicando que os temas que são gerenciados são mais emergentes e menos planejados. Várias linhas de ação estratégica são adotadas, entretanto existem outras que devem ser incorporadas. O sistema de controle estratégico Balanced Scorecard mostrouse pouco eficiente, pois desconsidera várias etapas importantes que um sistema de gestão da sustentabilidade deve medir. Isso induz a necessidade de revisão dos modelos conceituais e aplicados pelas empresas.

\section{REFERÊNCIAS}

Bardin, 1. (1977). Análise de conteúdo. Lisboa: Edições 70.

Boron, S., \& Murray, K. (2004). Bridging the unsustainability gap: a framework for sustainable development. Sustainable Development, 12(2), 65-73.

Egri, C. P., \& Pinfield, L. T. (2001). As organizações e a biosfera: ecologia e meio ambie. In S. T. CLEGG, W. R. NORD \& C. HARDY (Eds.), Handbook de estudos organizacionais. São Paulo: Atlas.

Fiksel, J. R. (1996). Design for environment : creating eco-efficient products and processes / Joseph Fiksel, editor. New York :: McGraw-Hill. 
Gunnigham, N., \& Sinclair, D. (1997). Barriers and motivators to the adoption of cleaner production practices. Canberra: ACEL Final report.

Iyer-Raniga, U., \& Treloar, G. (2000). A context for participation in sustainable development. Environmental Management, 26(4), 349-361.

Kay, J. J., Regier, H. A., Boyle, M., \& Francis, G. (1999). An ecosystem approach for sustainability: addressing the challenge of complexity. Futures, 31, 711.

Merrian, S. B. (1998). Research and case study. Applications em educations. São Francisco: JosseyBass Publishers.

Nascimento, L. F., Lemos, Â. D. d. C., \& Mello, M. C. A. d. (2008). Gestão socioambiental estratégica. Porto Alegre: Bookmann.

Peneda, C., \& Frazão, R. (1994). Ecodesign no desenvolvimento dos produtos. Lisboa: Instituto Nacional de Engenharia e Tecnologia Industrial.

Robert, K. H. (2000). Tools and concepts for sustainable development, how do they relate to a general framework for sustainable development, and to each other? Journal of Cleaner Production, 8, 243-254.

Robèrt, K. H., Schmidt-Bleek, B., Aloisi de Larderel, J., Basile, G., Jansen, J. L., Kuehr, R., et al. (2002). Strategic sustainable development -- selection, design and synergies of applied tools. Journal of Cleaner Production, 10(3), 197-214.

Srivastava, S. K. (2007). Green supply-chain management: A state-of-the-art literature review. International Journal of Management Reviews, 9(1), 53-80.

Trivinõs, A. N. S. (1987). Introdução a pesquisa em ciências sociais: a pesquisa qualitativa em educação. São Paulo: Atlas.

UNEP/IE. (1996). Manual - Lifecycle Design Strategies. The Netherlands: UNEP/IE.

Waage, S. A., Geiser, K., Irwin, F., Weissman, A. B., Bertolucci, M. D., Fisk, P., et al. (2005). Fitting together the building blocks for sustainability: a revised model for integrating ecological, social, and financial factors into business decision-making. Journal of Cleaner Production, 13(12), 1145-1163.

Data do recebimento do artigo: 18/08/2010

Data do aceite de publicação: 26/03/2011

Revista de Gestão Social e Ambiental - RGSA, São Paulo, v.5, n.1, p. 109-122, jan./abr., 2011. 